\title{
Numerical and Experimental Study of the Impeller of a Liquid Pump of a Truck Cooling System and the Development of a New Open-Type Impeller
}

\author{
Rishat Salakhov, Andrey Ermakov, Elvira Gabdulkhakova
}

\begin{abstract}
Typically, closed-type impellers are more efficient than open-type impellers, but in the manufacture of closed-type impellers, cost of wheels is higher. This paper describes the development of cost-effective and simple impeller wheel for a fluid pump in the truck cooling system. To perform this task, the numerical computations of a standard impeller wheel were carried out, its characteristics were also obtained from a test bench, the standard impeller wheel model was verified. The open-type impeller wheel was developed according to the current dimensions of standard impeller wheel and then analyzed with the numerical computations by the software ANSYS CFX (Academic license) computational fluid dynamics. The developed open-type impeller wheel works very effectively in spite of performance degradation by $5 \%$ in comparison to the closed-type impeller wheel. When working as a part of engine, the pump efficiency is $0.552-0.579$. The maximum value of the pump efficiency is 0.579 , it can be achieved at the highest speed of the pump $(4,548 \mathrm{rpm}$ and $655 \mathrm{l} / \mathrm{min})$.
\end{abstract}

Keywords: centrifugal pump; CFD analysis; experimental tests; numerical simulation; optimized design; performance characteristics

\section{INTRODUCTION}

Reducing $\mathrm{CO}_{2}$ emissions is an urgent task today. Transport is currently responsible for around a quarter of total greenhouse gas emissions, with road transport representing $17.8 \%$ of total emissions, arising from the use of vehicles. The European Automobile Manufacturers Association (ACEA) program has been developed to reduce $\mathrm{CO}_{2}$ emissions from trucks by $7 \%$ by 2025 and $16 \%$ by 2030 [1]. One way to reduce $\mathrm{CO}_{2}$ emissions is to use highly efficient engines. At present, Kama Automobile Plant (KAMAZ PJSC manufacturer located in Naberezhnye Chelny, Russian Federation) is actively developing highly efficient engines, one of which is the 6-cylinder diesel engine to be launched in the nearest future. This engine has reduced $\mathrm{CO}_{2}$ emissions due to its high power density and efficiency. The increasing power leads to the additional requirement to the cooling system. Today, it is planned to use a pump impeller with a cover disk (closed-type). The closed-type impeller wheel has two disks with blades in between. It creates a good pressure and is characterized by small leaks of water from the exit to the entrance. These impellers are produced in several ways: stamping, casting, spot welding or riveting. Despite the high efficiency, the pump impeller with the cover disk is more difficult to manufacture, which affects the cost of the finished product.

Another area to reduce $\mathrm{CO}_{2}$ emissions is to reduce emissions from truck production. Commercial vehicle manufacturer MAN Truck \& Bus (Germany) has reduced the $\mathrm{CO}_{2}$ emissions of its production facilities by more than one quarter [2]. The use of a simpler impeller technology for the engine cooling system is also one of the ways to reduce $\mathrm{CO}_{2}$ emissions, which will also reduce the impeller cost.

Therefore, the main goal of this work is developing the cost-effective and simple impeller wheel with the same high efficiency and pressure. The goal of this engineering research is to design the impeller wheel without the cover disk based on the standard impeller wheel geometry with its external dimensions kept unchanged.

\section{MATERIAL AND METHODS \\ 2.1 Research Model}

The new open-type impeller wheel was developed according to the methodology generally accepted in Russia [3], which is also in line with the methods accepted worldwide for calculating impeller machines described in [4]. According to the set dimensions, this methodology allows to calculate angles of the flow entry and flow exit to the impeller, as well as the wheel thickness at the entry and exit points. The methodology of numerical calculation is similar to [5].

Initial data for the calculation:

Volumetric flow rate: $Q=5001 / \mathrm{min}$; Engine speed: $n=$ $3373 \mathrm{rpm} ; \omega=\pi n / 30=353.2201 / \mathrm{s}$; Head: $H=18.096 \mathrm{~m}$.

Determination of the main parameters of the blade according to the method given in [1]:

Speed factor: $n_{\mathrm{s}}=3.65 \cdot n \cdot \frac{\sqrt{Q}}{\sqrt[4]{H^{3}}}$;

The reduced diameter of the entrance to the wheel: $D_{1}=4.5 \cdot \sqrt[3]{\frac{Q}{n}} ;$

Hydraulic efficiency: $n_{\mathrm{g}}=1-\frac{0.42}{\left(\log \left(1000 \cdot D_{1}\right)-0.172\right)^{2}}$;

Volumetric efficiency: $\eta_{\mathrm{V}}=\frac{1}{1+0.68 \cdot \frac{1}{\sqrt[3]{n_{\mathrm{s}}^{2}}}}$;

Internal mechanical efficiency: $\eta_{\mathrm{m}}=\frac{1}{1+\frac{820}{n_{\mathrm{s}}^{2}}}$; 
Entry speed: $C_{0}=0.08 \cdot \sqrt[3]{Q \cdot n^{2}}$;

Blade inlet diameter: $D_{0}=\sqrt{4 \cdot \frac{Q_{\mathrm{T}}}{\pi \cdot C_{0}}+d_{\mathrm{CT}}^{2}}$;

The radial velocity flow at the beginning of blade: $C_{1 \mathrm{r}}=\frac{C_{0}}{\psi_{1}}$;

Initial blade width: $b_{1}=\frac{Q}{C_{1 \mathrm{r}} \cdot \pi \cdot D_{1} \cdot \psi_{1}}$;

Peripheral speed: $U_{1}=D_{1} \cdot \pi \cdot \frac{n}{60}$;

The initial angle of the flow on blades: $\beta_{1}=\frac{180}{\pi} \cdot \arctan \left(\frac{C_{1 \mathrm{r}}}{U_{1}}\right)$;
End angle of blade flow:

$$
\beta_{2}=\frac{180}{\pi} \cdot \arcsin \left(C_{2 \mathrm{r}} \cdot \frac{\omega_{1}}{\omega_{2}} \cdot \frac{\sin \beta_{1}}{C_{1 \mathrm{r}}}\right) ;
$$

Outlet peripheral speed:

$$
\begin{array}{r}
U_{2}=\frac{C_{2 \mathrm{r}}}{2 \cdot \tan \beta_{2}}+\sqrt{\frac{C_{2 \mathrm{r}}^{2}}{\left(2 \cdot \tan \beta_{2}\right)^{2}}+9.81 \cdot H_{\infty}} ; \\
\text { Final blade width: } b_{2}=\frac{Q_{\mathrm{T}}}{C_{2 \mathrm{r}} \cdot \pi \cdot D_{2} \cdot \psi_{2}} .
\end{array}
$$

The original closed-type impeller wheel is shown in Fig. $1 \mathrm{a}$ ), and the modified open-type impeller wheel calculated according to the methodology above is shown in Fig. 1 b).

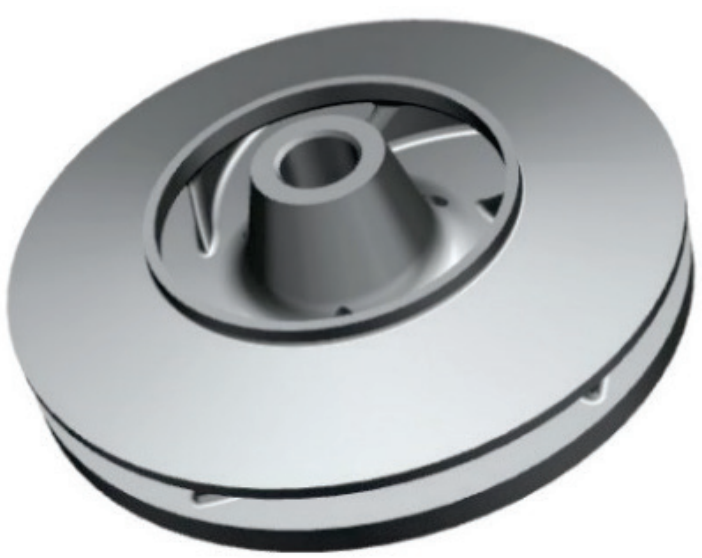

a)

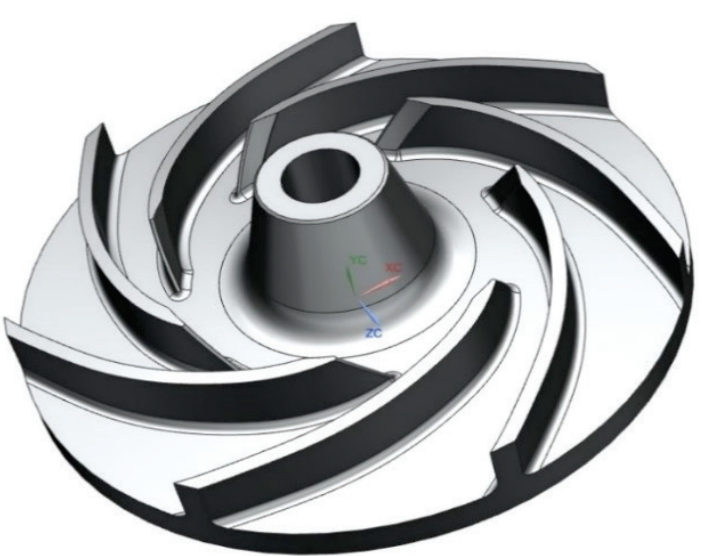

b)

Figure 1 Impellers of the liquid pump: a) standard impeller (closed-type) wheel, b) modified impeller (open-type) wheel.
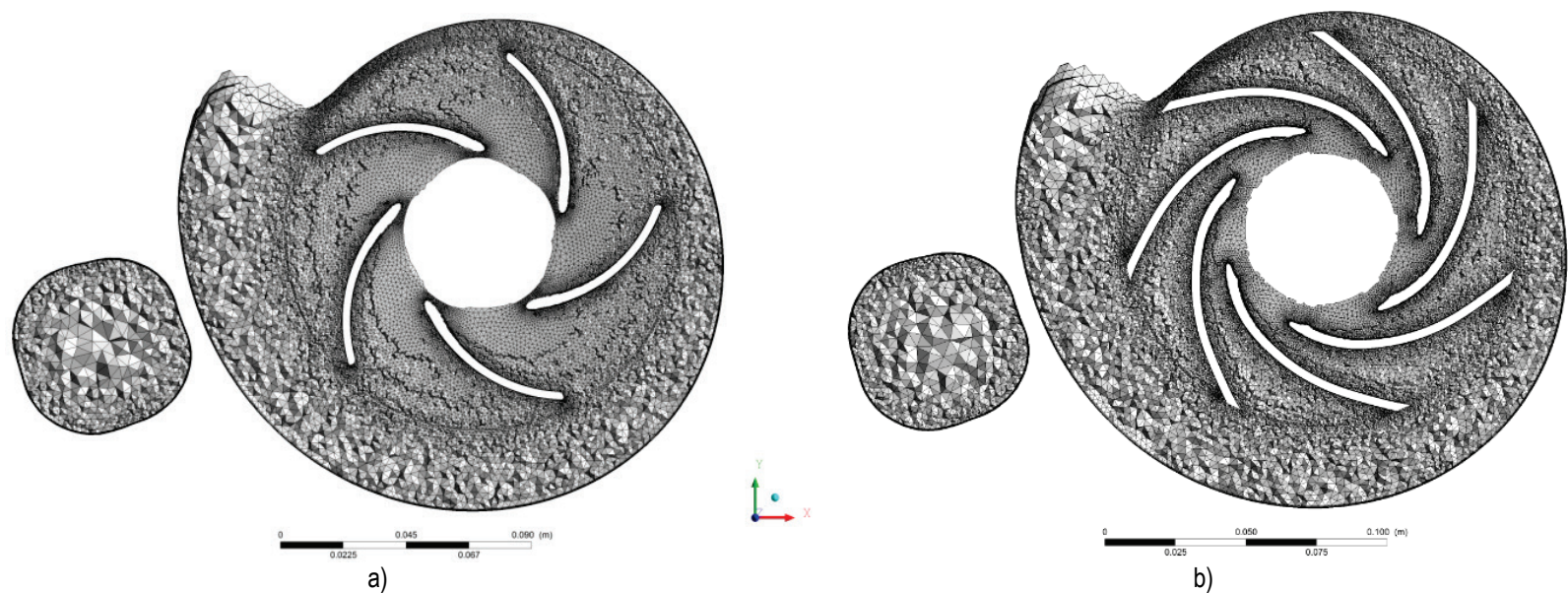

Figure 2 Pump mesh section: a) standard impeller wheel, b) modified impeller wheel.

\subsection{Creating a Mesh}

The mesh is created based on the domain section in the mesh generator software - Ansys Meshing. The hybrid, unstructured mesh consists of tetrahedral and prismatic elements. The prismatic boundary level also consists of seven layers for correct modelling the hydrodynamics of the near- wall flow. Fig. 2 depicts the mesh generated in Meshing software.

The computational model of the liquid pump is created in the Ansys CFX pre-processor based on the generated mesh. The computational model consists of 3 rotor domains and 2 stators coupled through "FLOW - FLOW" interfaces. 
The following boundary conditions are determined for this model:

- Working medium is water

- $\quad$ Environmental pressure is $101325 \mathrm{~Pa}$

- Water temperature is $25^{\circ} \mathrm{C}$

- Outlet volumetric flow rate corresponds to the pumpworking mode (Tab. 1)

- Atmospheric inlet pressure

- The angle speed of the domain rotation corresponds to the design mode (Tab. 1).

The work modes of the liquid-ring vacuum pump for researching into its hydrodynamic characteristics are listed in Tab. 1 .

Table 1 The work modes of the liquid-ring vacuum for researching into its hydrodynamic characteristics

\begin{tabular}{|c|c|c|c|c|c|}
\hline Frequency & $\begin{array}{c}\text { Volumetric } \\
\text { flow rate }\end{array}$ & $\begin{array}{c}\text { Inlet } \\
\text { pressure }\end{array}$ & Frequency & $\begin{array}{c}\text { Volumetric } \\
\text { flow rate }\end{array}$ & $\begin{array}{c}\text { Inlet } \\
\text { pressure }\end{array}$ \\
\hline$n, \mathrm{rpm}$ & $Q, 1 / \mathrm{min}$ & $P_{\text {in }}, \mathrm{Pa}$ & $n, \mathrm{rpm}$ & $Q, 1 / \mathrm{min}$ & $P_{\text {in }}, \mathrm{Pa}$ \\
\hline 1370 & 80 & 0 & 3373 & 340 & 0 \\
\hline 1370 & 180 & 0 & 3373 & 500 & 0 \\
\hline 1370 & 280 & 0 & 3373 & 720 & 0 \\
\hline 1827 & 130 & 0 & 3373 & 780 & 0 \\
\hline 1827 & 260 & 0 & 3825 & 370 & 0 \\
\hline 1827 & 375 & 0 & 3825 & 570 & 0 \\
\hline 1827 & 450 & 0 & 3825 & 760 & 0 \\
\hline 2732 & 185 & 0 & 4548 & 3 & 0 \\
\hline 2732 & 405 & 0 & 4548 & 500 & 0 \\
\hline 2732 & 565 & 0 & 4548 & 655 & 0 \\
\hline & & & 4548 & 760 & 0 \\
\hline
\end{tabular}

In general, numerical studies of impeller wheels are carried out using k-e turbulence models with Fluent [6, 7] and CFX $[8,9]$, but this $\mathrm{k}$-e model does not ensure the required calculation accuracy. The k-w turbulence model $[10,11]$ is also used, which also gives discrepancies [12]. The greatest accuracy is ensured by the Shear Stress Transport (SST) $k-w$ turbulence model [13-15] with the accuracy confirmed by a Particle image velocimetry (PIV) study of the flow structure in $[4,16,17]$. The convergence of CFD calculation and experimental studies is up to $10 \%$ [18], but the SST $k-w$ model allows obtaining high convergence of calculation of $5.1 \%[6,19]$ and $3 \%$ [20]. In the model creation stage, the semiempirical model of the k-omega SST turbulence was chosen, since the k-omega SST provides an adequate description of the near-wall turbulence and sensitiveness to the border conditions in the external flow. The authors already have experience in performing similar work when designing a centrifugal pump [21] and modeling heat transfer and hydrodynamics [22], where the k-omega SST model also showed good accuracy.

\section{EXPERIMENT}

The standard and new impeller wheels were tested for verification of the numerical model.

Figure 4 shows the principal hydraulic scheme of the experimental plant.

The experimental plant provides flow rates from 0 to 800 liters per minute.

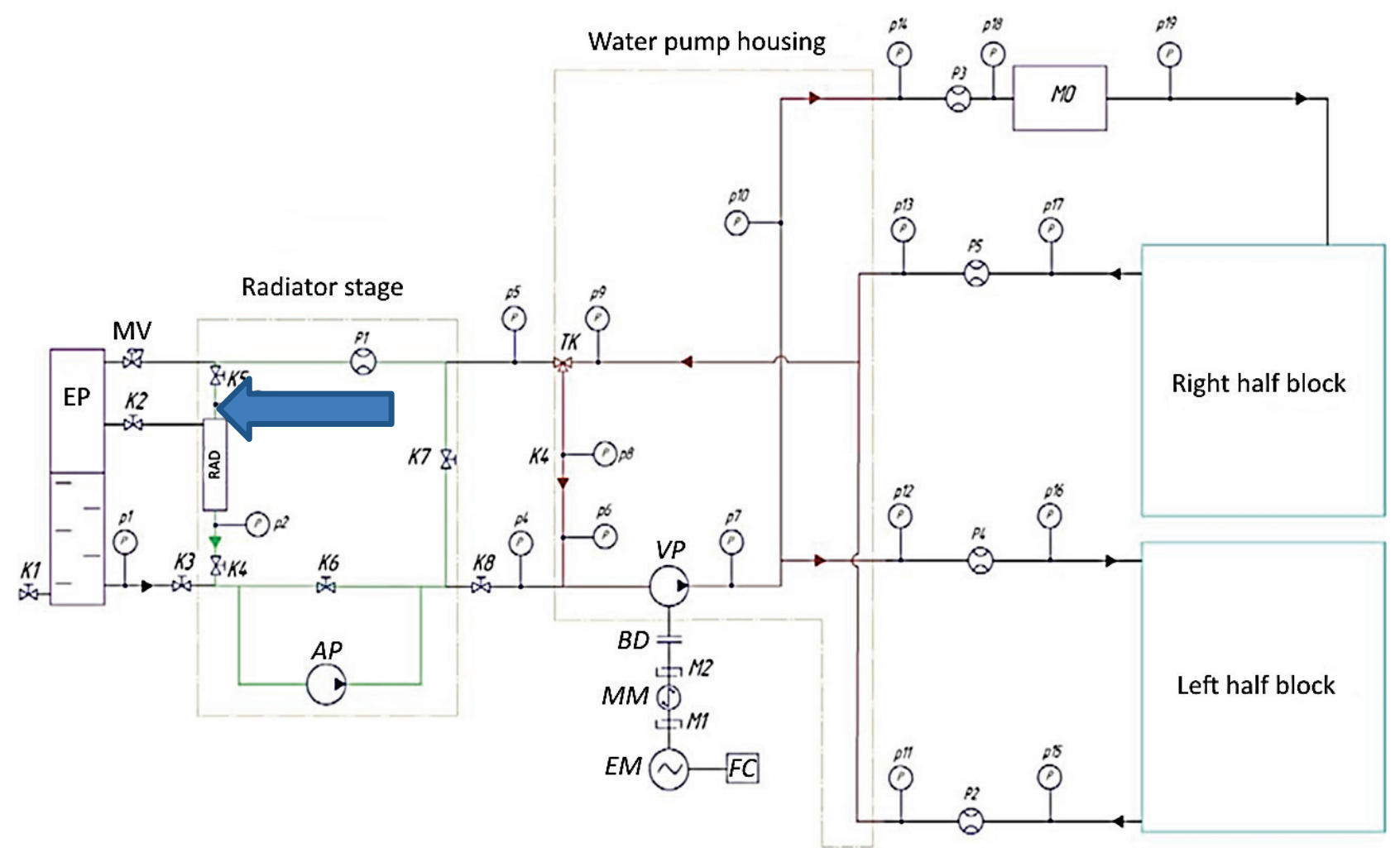

Figure 3 Principal scheme of the hydraulic stand: K1-K8 - globe valve, EP - expansion tank, MV - mixing valve, p1-p19 - pressure transmitter, RAD - cooler, AP adjustable cradle-mounted pump, TK - thermostat housing, VP - water pump, BD - belt-drive, M1-M2 - compensating clutch, MM - torque sensor, EM - electromotor, FC - frequency convertor, MO - oil cooler, P1-P5 - magnetic induction flow-meter. 


\section{RESULTS AND DISCUSSION \\ 4.1 Numerical Modeling Results \\ 4.1.1 Standard Impeller Results}

The results of numerical modelling determined integral hydrodynamic parameters of the standard impeller wheel in the different work modes: water streamlines in the pump (Fig. 5), velocity vectors in liquid pump section plane (Fig. 6), velocity profile in liquid pump section plane at mode (Fig. 7) and pressure profile in liquid pump section plane (Fig. 8).
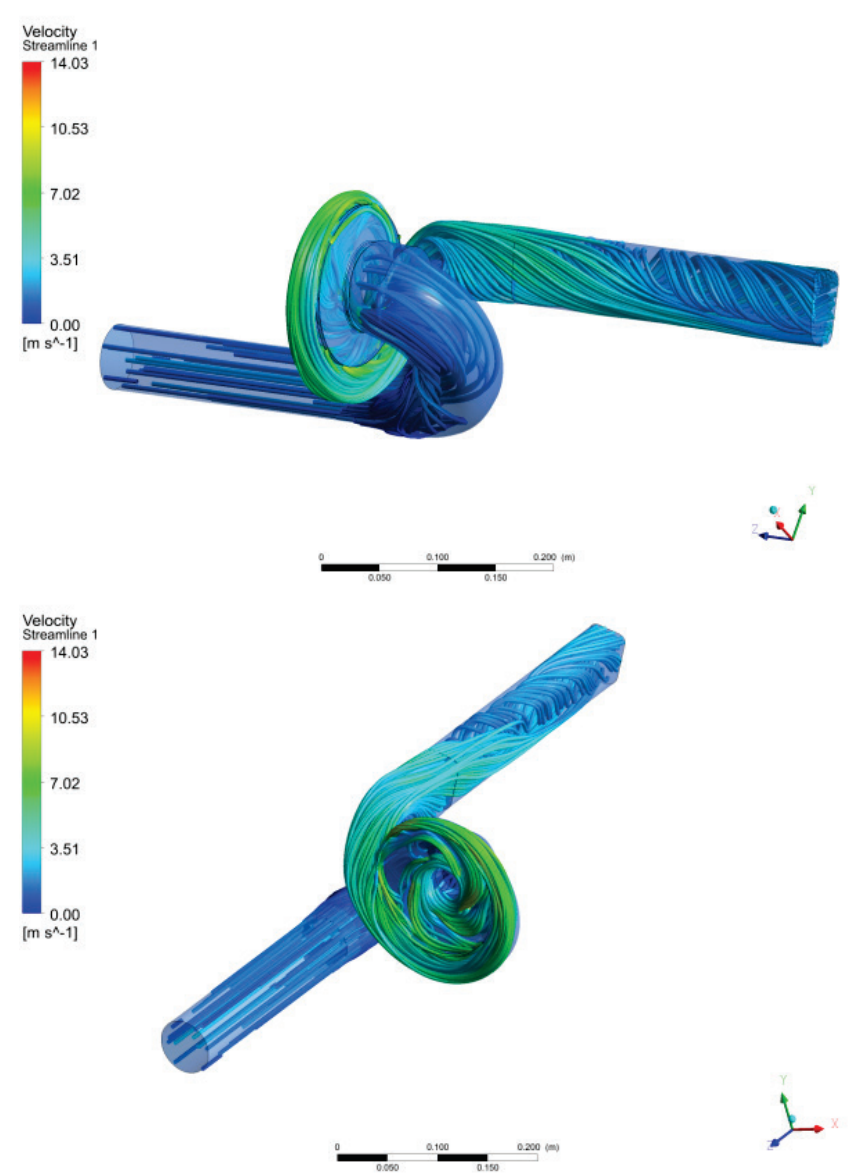

Figure 5 Water streamlines in liquid pump at mode $1827 \mathrm{r} / \mathrm{min}$ and $260 \mathrm{l} / \mathrm{min}$

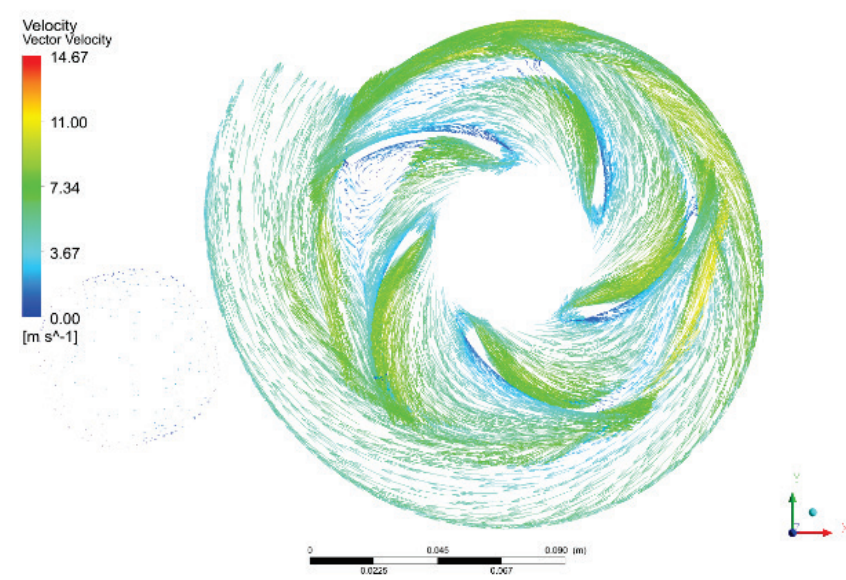

Figure 6 Velocity vectors in liquid pump section plane at $1827 \mathrm{rpm}$ and $260 \mathrm{l} / \mathrm{min}$
The flow structure at the output to the pump is uniform. At the output, you can notice a swirl of the flow, but without obvious flow interruptions, which affects the pump operation.

The cross-section of the pump also shows welldistributed velocity vectors without flow interruptions, but the velocity field shows that flow may disrupt at the end of the blades, which can cause additional flow turbulence and hydraulic losses.

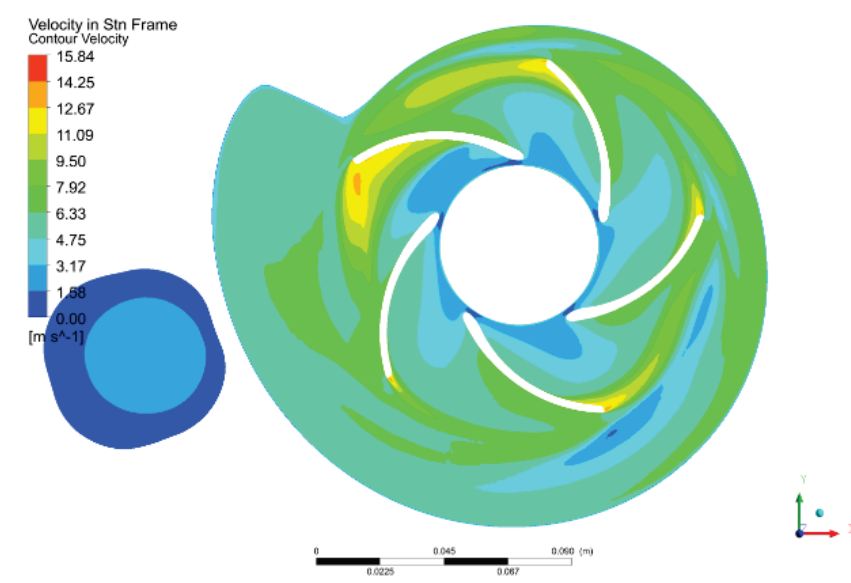

Figure 7 Velocity profile in liquid pump section plane at $1827 \mathrm{rpm}$ and $260 \mathrm{l} / \mathrm{min}$

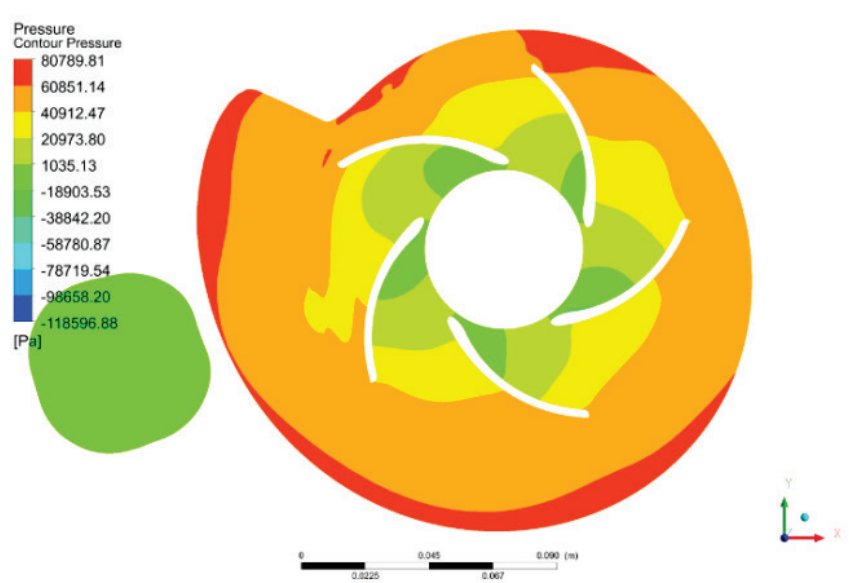

Figure 8 Pressure profile in liquid pump section plane at $1827 \mathrm{rpm}$ and $260 \mathrm{l} / \mathrm{min}$.

The pressure field shows a uniform pressure increase without obvious flow separations.

Table 2 Results of the numerical research of the liquid pump

\begin{tabular}{|c|c|c|c|c|c|c|c|}
\hline $\begin{array}{c}n, \\
\text { rpm }\end{array}$ & $\begin{array}{c}Q, \\
1 / \mathrm{min}\end{array}$ & $h, \mathrm{~m}$ & Efficiency & $\begin{array}{c}n, \\
\mathrm{rpm}\end{array}$ & $\begin{array}{c}Q, \\
1 / \mathrm{min}\end{array}$ & $h, \mathrm{~m}$ & Efficiency \\
\hline 1370 & 80 & 4.350 & 0.323 & 3373 & 340 & 23.911 & 0.537 \\
\hline 1370 & 180 & 3.620 & 0.552 & 3373 & 500 & 20.571 & 0.578 \\
\hline 1370 & 280 & 2.516 & 0.518 & 3373 & 720 & 14.172 & 0.505 \\
\hline 1827 & 130 & 7.380 & 0.386 & 3373 & 780 & 11.852 & 0.447 \\
\hline 1827 & 260 & 6.170 & 0.571 & 3825 & 370 & 31.039 & 0.529 \\
\hline 1827 & 375 & 4.486 & 0.522 & 3825 & 570 & 26.287 & 0.575 \\
\hline 1827 & 450 & 2.709 & 0.361 & 3825 & 760 & 20.617 & 0.545 \\
\hline 2732 & 185 & 16.584 & 0.376 & 4548 & 3 & 56.496 & 0.005 \\
\hline 2732 & 405 & 13.512 & 0.577 & 4548 & 500 & 42.322 & 0.550 \\
\hline 2732 & 565 & 9.925 & 0.522 & 4548 & 655 & 37.747 & 0.579 \\
\hline & & & & 4548 & 760 & 34.370 & 0.570 \\
\hline
\end{tabular}


Table 3 Results of the numerical studies of the liquid pump in the engine assembly

\begin{tabular}{|c|c|c|c|}
\hline$n, \mathrm{rpm}$ & $Q, 1 / \mathrm{min}$ & $h, \mathrm{~m}$ & Efficiency \\
\hline 1370 & 180 & 3.620 & 0.552 \\
\hline 1827 & 260 & 6.170 & 0.571 \\
\hline 2732 & 405 & 13.512 & 0.577 \\
\hline 3373 & 500 & 20.571 & 0.578 \\
\hline 3825 & 570 & 26.287 & 0.575 \\
\hline 4548 & 655 & 37.747 & 0.579 \\
\hline
\end{tabular}

In addition, the engine hydraulic characteristic (EHC) was numerically determined.

\section{COMPUTATION VERIFICATION AND CONCLUSION}

Fig. 9 and Tab. 4 show the comparison results of the numerical calculations and experimental studies. Here we see a good convergence of the numerical and experimental studies results not exceeding $9 \%$ in the engine operating modes, which is quite acceptable for this type of work. No further refinement of the numerical model is required.

Table 4 Relative error in the numerical computation of the liquid pump in the engine assembly

\begin{tabular}{|c|c|c|c|c|}
\hline $\begin{array}{c}n, \\
\mathrm{rpm}\end{array}$ & $\begin{array}{c}Q, \\
\mathrm{l} / \mathrm{min}\end{array}$ & $\begin{array}{c}h \text { (experiment), } \\
\mathrm{m}\end{array}$ & $\begin{array}{c}h \text { (computation), } \\
\mathrm{m}\end{array}$ & $\begin{array}{c}\text { Relative error, } \\
\%\end{array}$ \\
\hline 1370 & 180 & 3.581 & 3.620 & 0.474 \\
\hline 1827 & 260 & 6.193 & 6.170 & 0.376 \\
\hline 2732 & 405 & 14.451 & 13.512 & 6.483 \\
\hline 3373 & 500 & 22.083 & 20.571 & 6.808 \\
\hline 3825 & 570 & 28.790 & 26.287 & 8.704 \\
\hline 4548 & 655 & 39.241 & 37.747 & 3.820 \\
\hline
\end{tabular}

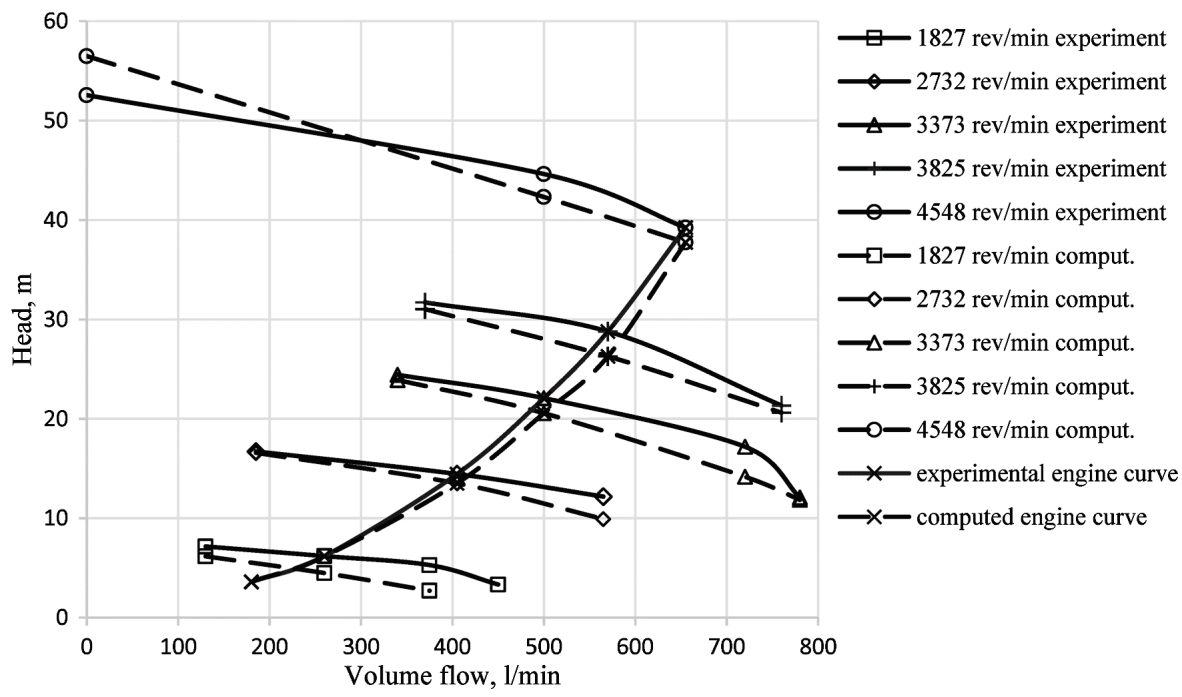

Figure 9 Computed head liquid pump characteristic of the 920.10-700 KAMAZ R6 engine
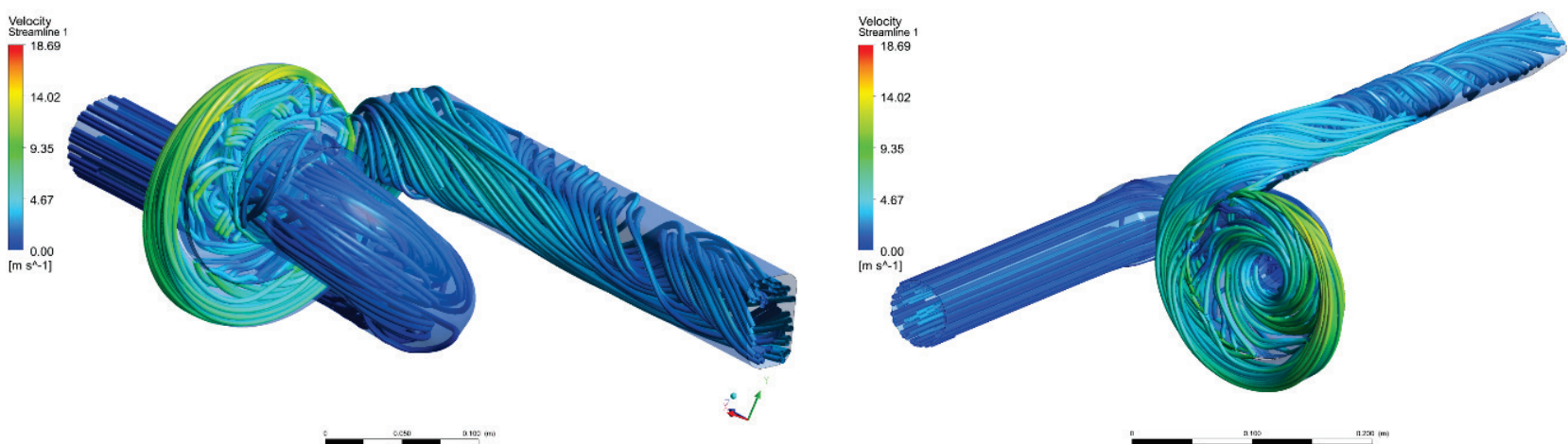

Figure 10 Water streamlines in a liquid pump with the modified impeller at $1827 \mathrm{rpm}$ and $260 \mathrm{l} / \mathrm{min}$

\subsection{Modified Impeller Results}

Verification of the numerical study and experimental results of the water pump with a standard wheel show the minor error of the computational model. Therefore, this model may be used to test the modified wheel.

The results of numerical modelling determined integral hydrodynamic parameters of the modified impeller wheel at different work modes: water streamlines in the pump (Fig. 10), velocity vectors in liquid pump section plane (Fig. 11), velocity profile in liquid pump section plane (Fig. 12) and pressure profile in liquid pump section plane (Fig. 13)

The flow structure at the pump input is uniform. At the output, you can notice a swirl of the flow without obvious flow interruptions, which affects the pump operation.

Unlike a standard impeller, the speed between the blades of the modified impeller is uniform, which means a more cavitation-resistant design. 
The pressure in the modified impeller is increasing even more evenly than that in the standard impeller, which also indicates a good design.

According to the results of the numerical study, the characteristics of the modified impeller are better in the entire range of operation of rotors and fluid flow rates.

Table 5 Results of the numerical study for the liquid pump with the modified impeller

\begin{tabular}{|c|c|c|c|c|c|c|c|}
\hline $\begin{array}{c}n, \\
\text { rpm }\end{array}$ & $\begin{array}{c}Q, \\
1 / \mathrm{min}\end{array}$ & $h, \mathrm{~m}$ & Efficiency & $\begin{array}{c}n, \\
\mathrm{rpm}\end{array}$ & $\begin{array}{c}Q, \\
1 / \mathrm{min}\end{array}$ & $h, \mathrm{~m}$ & Efficiency \\
\hline 1370 & 80 & 5.60 & 0.43 & 3373 & 340 & 30.43 & 0.25 \\
\hline 1370 & 180 & 4.60 & 0.43 & 3373 & 500 & 27.63 & 0.51 \\
\hline 1370 & 280 & 3.47 & 0.60 & 3373 & 720 & 19.45 & 0.52 \\
\hline 1827 & 130 & 10.01 & 0.61 & 3825 & 370 & 40.29 & 0.57 \\
\hline 1827 & 260 & 8.07 & 0.51 & 3825 & 570 & 35.58 & 0.51 \\
\hline 1827 & 375 & 6.18 & 0.40 & 3825 & 760 & 28.21 & 0.41 \\
\hline 2732 & 185 & 22.84 & 0.62 & 4548 & 500 & 54.06 & 0.54 \\
\hline 2732 & 405 & 15.13 & 0.70 & 4548 & 655 & 50.14 & 0.51 \\
\hline 2732 & 565 & 13.73 & 0.40 & 4548 & 760 & 46.37 & 0.78 \\
\hline
\end{tabular}
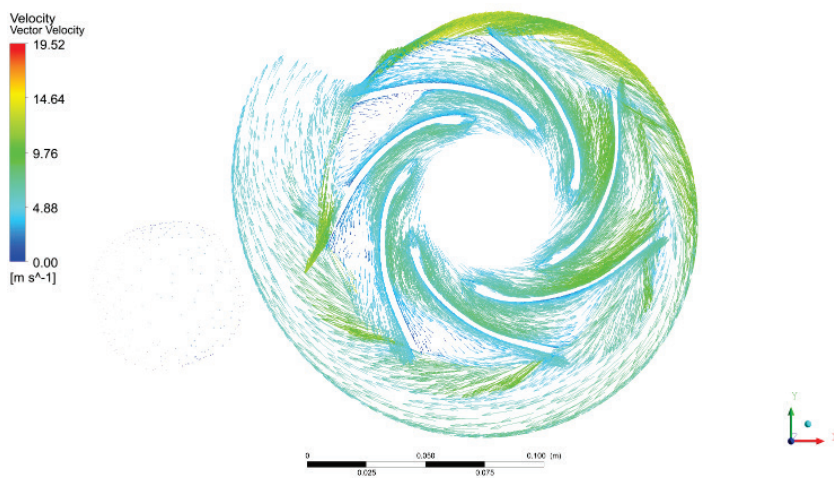

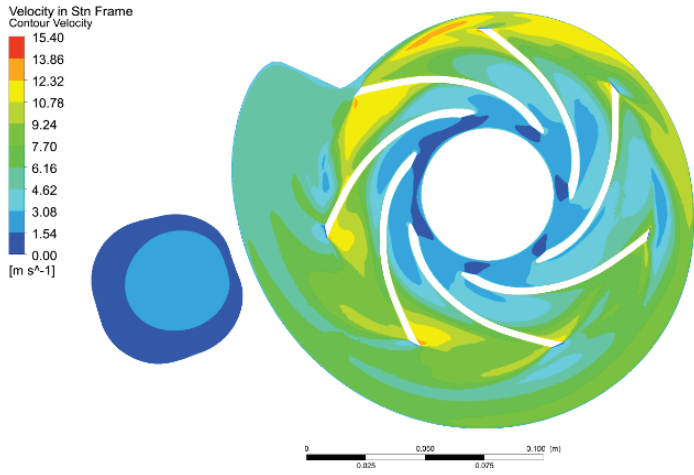

$\stackrel{\lfloor}{\leftrightarrow}$

Figure 12 Velocity profile in liquid pump with the modified impeller section plane at $1827 \mathrm{rpm}$ and $260 \mathrm{l} / \mathrm{min}$

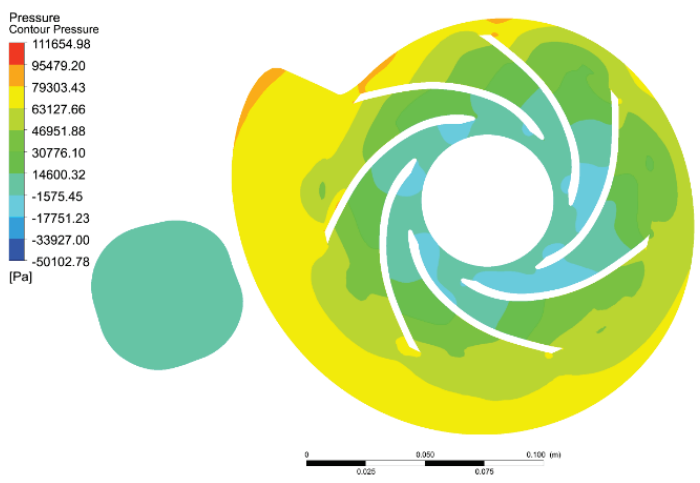

Figure 13 Pressure profile in the liquid pump with modified impeller section plane at $1827 \mathrm{rpm}$ and $260 \mathrm{l} / \mathrm{min}$

Figure 11 Velocity vectors in liquid pump with the modified impeller section plane at $1827 \mathrm{rpm}$ and $260 \mathrm{l} / \mathrm{min}$

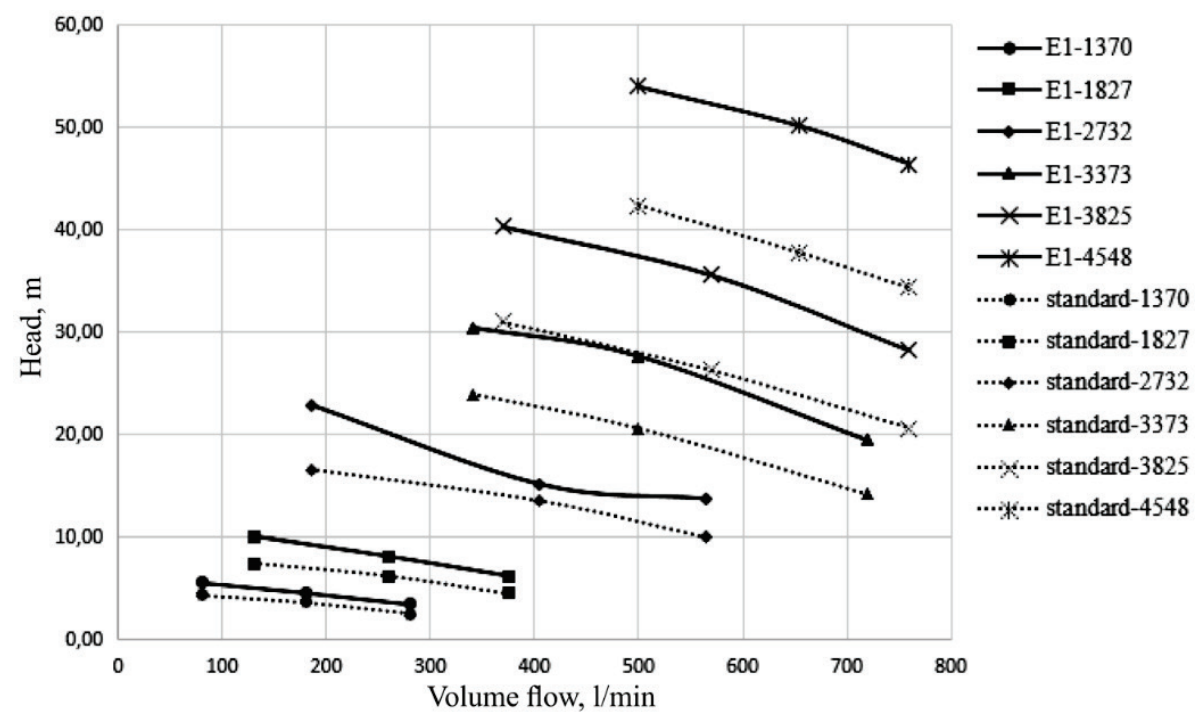

Figure 14 Comparing numerical results of hydraulic characteristic for standard and modified impellers of the liquid pump for the 920.10-700 KAMAZ R6 engine.

\subsection{Experimental Results}

After manufacturing the plastic modified impeller using the FDM (fused deposition modeling) 3D printing method, it was used for the experimental studies, the results of which are presented in Fig. 15.
Fig. 15 shows a degradation in the characteristics of the modified impeller with an increase in fluid flow, which is possibly associated with the manufacturing technology and an uneven surface that causes additional turbulence. 


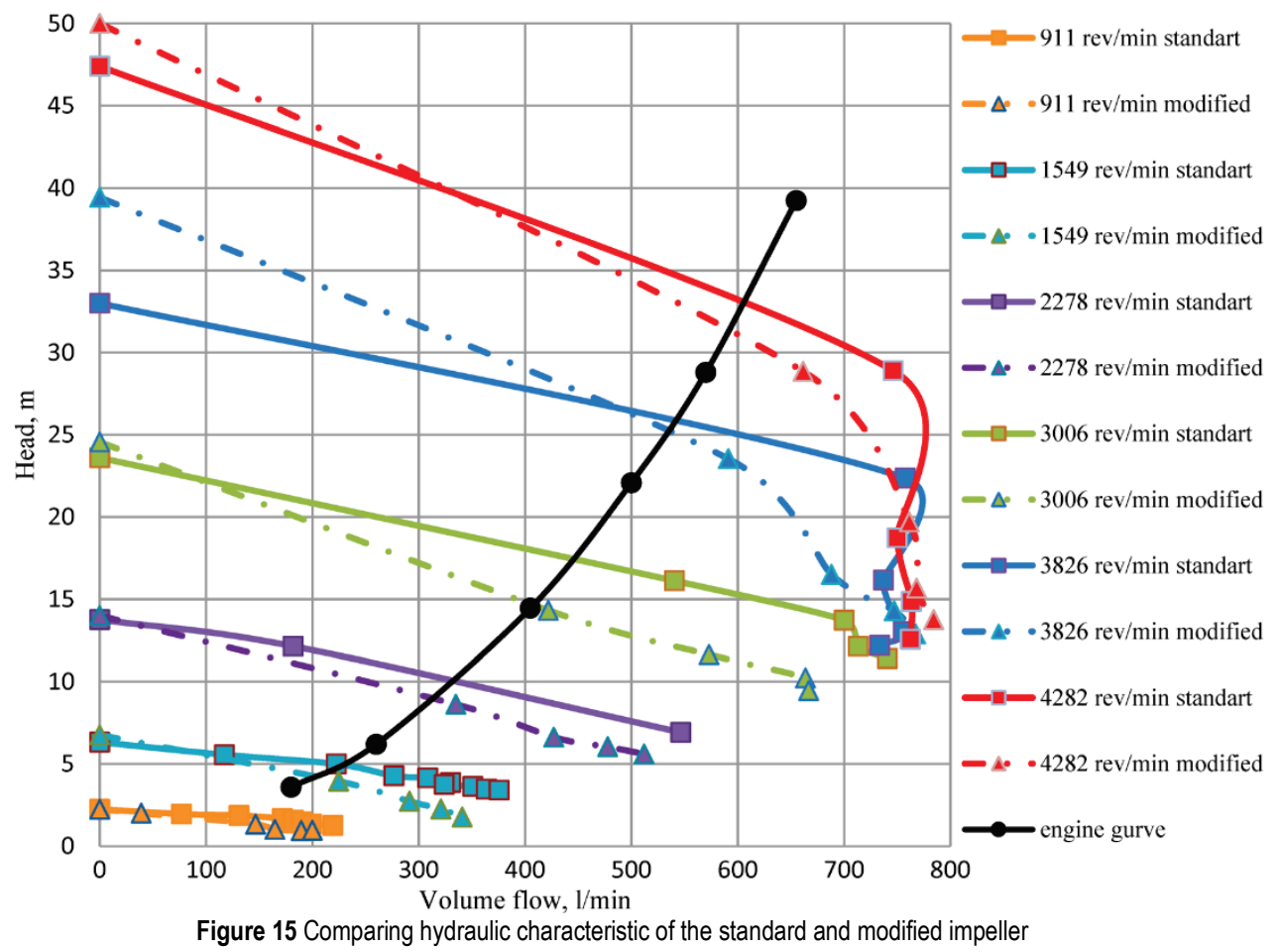

\section{DISCUSSION}

The verification of the numerical computations with experimental results showed that at the low-pressure values the design values and the experimental values are the same. Based on the results depicted in Tab. 4, the average relative error of the computations is $8.2 \%$. The accuracy of the calculations is a little higher than that in the works $[6,19,20]$, but acceptable, and no further refinements of the numerical model are required.

The verification of the numerical computations with experimental results in the engine assembly showed that $\mathrm{EHC}$ and the average relative error is the same and equal to $4.45 \%$ (Tab. 4 ).

The investigated liquid pump is highly efficient in the engine assembly. Its efficiency ranges from 0.552 to 0.579 . The maximum efficiency value is 0.579 at $4558 \mathrm{rpm}$ and 655 $1 /$ min flow rate. These efficiency characteristics are acceptable for open-type impellers, and in our work they are even better than those in the article [4].

The numerical modelling allows to understand the flow distribution inside the pump and how the velocity and pressure (static and absolute) distribute at steady-state and unsteady-state water flow in the flow part. Obviously, taking into account the manufacturing method of FDM 3D printing, these data could not be obtained in the experimental tests, and it is necessary to choose a more expensive, but high-quality printing technology like SLA.

The computational pump model created in Ansys CFX software has been verified successfully. Consequently, it has proved that the software could be used for numerical computations. Numerical tests in the Ansys CFX software allows to optimize the impeller wheel, flow part of the pump, flow part, scroll for improving the 920.10-700 KAMAZ R6 engine pump. As a result, it is possible to improve the power capacity and steady operation of the cooling system of the 920.10-700 KAMAZ R6 diesel engine. In addition, it allows reducing the time and cost of material resources required for creating and optimizing the elements of the engine cooling system.

\section{CONCLUSION}

The study conducted in this paper suggests the possibility of replacing a closed-type impeller with an opentype wheel with a slight loss of efficiency. The main disadvantage of an open wheel is a low efficiency of about $40 \%$. Closed impellers are $10-15 \%$ more efficient than opentype impeller wheels, but also have a higher manufacturing cost. In this work, an open-type impeller wheel was developed directly under the required flow rate and head, which reduced the performance decrease by $5 \%$ and overall efficiency is about $57 \%$ at nominal flow rate. The manufacture of an open-type impeller is much simpler, simple forms can be used, which also reduces energy costs for the manufacture of molds. The closed-type impeller must be made by casting according to the investment casting only and has complex rods. Starting to use the open-type wheels will significantly reduce $\mathrm{CO}_{2}$ emissions in wheel casting in the truck production. As for the cost, the open-type wheel is approximately 2 times cheaper.

\section{Acknowledgements}

This work was supported by the Scholarships of the President of the Russian Federation. 


\section{REFERENCES}

[1] Reuters, Philip Blenkinsop, EU countries agree to 30 percent cut in truck $\mathrm{CO}_{2}$ emissions, Date of publication 20 December 2018, https://www.reuters.com/article/us-eu-autos-emissions/eucountries-agree-to-30-percent-cut-in-truck-co2-emissionsidUSKCN1OJ1ZC (Accessed: 09.10.2019).

[2] Volkswagen, News, MAN cuts its plants' $\mathrm{CO}_{2}$ emissions by over a quarter, Date of publication 14 May 2019, https://www.volkswagenag.com/en/news/2019/05/man_co2_e missions.html Munich, (Accessed: 09.10.2019).

[3] Ivanovsky, V. N., Sabirov, A. A., Degovtsov, A. V., Beijing, S. S., Donskoy, Yu. A., Krivenkov, S. V., Sokolov, N. N., \& Kuzmin, A. V. (2014). Design and study of the characteristics of the degrees of dynamic pumps. The educational publication for the research work of undergraduates in the direction. Designing machinery and equipment for the operation of oil and gas wells. Moscow: Gubkin Russian State University of Oil and Gas.

[4] Liu, J., Zhao, X., \& Xiao, M. (2015). Study on the Design Method of Impeller on Low Specific Speed Centrifugal Pump. The Open Mechanical Engineering Journal, 9, 594-600. https://doi.org/10.2174/1874155X01509010594

[5] López, R., Vaca, M. et al. (2017). Performance simulation of a radial flow type impeller of centrifugal pumps using CFD. IOP Conf. Series: Journal of Physics: Conf. Series, 792. https://doi.org/10.1088/1742-6596/792/1/012029

[6] Wei, D. \& Wu, L. C. (2018). Numerical Investigation of the Fluid Flow Characteristics in the Hub Plate Crown of a Centrifugal Pump. Chin. J. Mech. Eng., 31, 64. https://doi.org/10.1186/s10033-018-0264-z

[7] Gamal, R. H., Elyamin, A., Bassily, A. M. et al. (2019). Effect of impeller blades number on the performance of a centrifugal pump. Alexandria Engineering Journal, 58, 39-48. https://doi.org/10.1016/j.aej.2019.02.004

[8] Bellary, S. A. I. \& Samad, A. (2016). Pumping crude oil by centrifugal impeller having different blade angles and surface roughness. J Petrol Explor Prod Technol, 6, 117-127. https://doi.org/10.1007/s13202-015-0173-y

[9] Shyam, N. S., Khare, R., \& Prasad, V. (2017). CFD approach for off-design efficiency improvement of double suction centrifugal pump. International Journal of Mechanical and Production Engineering Research and Development (IJMPERD), 7(5), 289-300. https://doi.org/10.24247/ijmperdoct201730

[10] Shuai, Z-J., Jiang, C-X. et al. (2015). Numerical simulation of dynamic flow characteristics in a centrifugal water pump with three-vaned diffuser. Advances in Mechanical Engineering, 7(8), 1-12. https://doi.org/10.1177/1687814015598487

[11] Dvořák, V. \& Müller, M. (2018). Preliminary investigation of centrifugal pump for fire engine. MATEC Web of Conferences, 210, Article Number 04015. https://doi.org/10.1051/matecconf/201821004015

[12] Du, J., Yang, H., \& Shen, Z. (2018). Study on the impact of blades wrap angle on the performance of pumps as turbines used in water supply system of high-rise buildings. International Journal of Low-Carbon Technologies, 13, 102108. https://doi.org/10.1093/ijlct/cty002

[13] Deng, S-S., Li, G-D. et al. (2019). Numerical study of cavitation in centrifugal pump conveying different liquid materials. Results in Physics, 12, 1834-1839. https://doi.org/10.1016/j.rinp.2019.02.009

[14] Xin, J. \& Lei, Z. (2017). Research on the effect of rotation and curvature on turbulence model and their application. International Journal of Heat and Technology, 35(1), 167-176. https://doi.org/10.18280/ijht.350122
[15] Murugesan, C. \& Rudramoorthy, D. R. (2016). Numerical And Experimental Study of Single stage And Multistage Centrifugal Mixed Flow Submersible Borewell Pumps. International Journal of Fluid Machinery and Systems, 9(2), 107-118. https://doi.org/10.5293/IJFMS.2016.9.2.107

[16] Zheng, X. Q. \& Wang, Y. (2018). Study on internal flow field simulation accuracy of centrifugal impellers based on different meshing types. IOP Conf. Series: Earth and Environmental Science, 163. Article Number 012019. https://doi.org/10.1088/1755-1315/163/1/012019

[17] Ren, Y., Zhu, Z. et al. (2016). An improved turbulence model for separation flow in a centrifugal pump. Advances in Mechanical Engineering, 8(6), 1-10. https://doi.org/10.1177/1687814016653310

[18] Moloshnyi, O. \& Szulc, P. (2018). The CFD simulation of the flow structure in the sewage pump. Open Engineering, 8, 314321. https://doi.org/10.1515/eng-2018-0035

[19] Wei, J., Diyi, C. et al. (2018). Experimental and numerical investigation on the influence of the clocking position on hydraulic performance of a centrifugal pump with guide vane. Journal of Vibroengineering, 20(6), 2469-2485. https://doi.org/10.21595/jve.2018.18758

[20] Kai, W., Zixu, Z. et al. (2017). Research on unsteady performance of a two-stage self-priming centrifugal pump. Journal of Vibroengineering, 19(3), 1732-1744. https://doi.org/10.21595/jve.2017.17287

[21] Gureev, V. M., Salakhov, R. R., Falyakhov, M. A., Kudusov, D. I., \& Burlakov, V. V. (2016). Development, research and production of a centrifugal impeller. Russian Aeronautics 59, 1. https://doi.org/10.3103/S1068799816010116

[22] Malganova, I. \& Ermakov. (2016). A. Numerical simulation of heat transfer and hydrodynamics ring and V-shaped heat exchange intensifiers. International Journal of Pharmacy and Technology, 8(4), 24300-24308.

\section{Authors' contacts:}

\section{Rishat Salakhov}

Department Heat and Power Engineering,

Kazan National Research Technical University named after A. N. Tupolev - KAI, 10, K. Marx str., Kazan, Tatarstan 420111, Russia

\section{Andrey Ermakov}

(Corresponding author)

Department Heat and Power Engineering,

Kazan National Research Technical University named after A. N. Tupolev - KAI, 10, K. Marx str., Kazan, Tatarstan 420111, Russia ermakov.kai@bk.ru

\section{Elvira Gabdulkhakova}

Department Heat and Power Engineering, Kazan National Research Technical University named after A. N. Tupolev - KAI, 10, K. Marx str., Kazan, Tatarstan 420111, Russia 